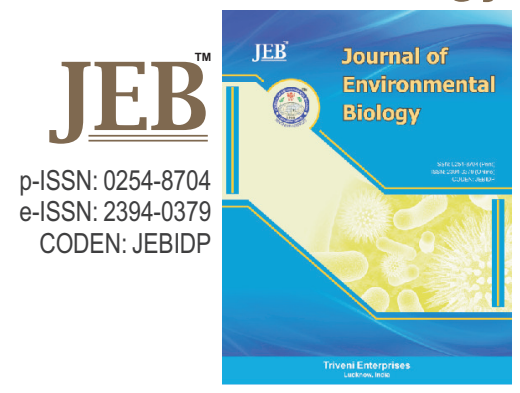

\title{
Stable isotope analysis as a tool for determining seafood provenance
}

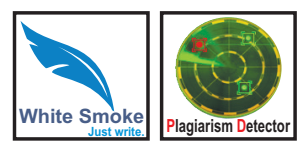

Authors Info

K. Gopi', D. Mazumder ${ }^{2 *}$, N. Saintilan ${ }^{3}$, F. Md. Yusoff and J. Sammut ${ }^{1}$

${ }^{1}$ Centre for Ecosystem Science, School of Biological, Earth and Environmental Sciences, University of New South Wales, Sydney, NSW 2052, Australia

${ }^{2}$ Australian Nuclear Science and Technology Organisation, Locked Bag 2001 Kirrawee DC, NSW 2232, Australia

${ }^{3}$ Department of Environmental Sciences, Macquarie University, Sydney, NSW 2109, Australia

${ }^{4}$ Faculty of Agriculture, Universiti Putra Malaysia 43400 UPM, Serdang, Selangor, Malaysia

${ }^{*}$ Corresponding Author Email : debashish.mazumder@ansto.gov.au

\section{Key words}

Barramundi

C:N ratio

Seafood provenance

Stable isotope analysis

Publication Info

Paper received : 08.09.2017

Revised received : 25.09 .2017

Re-revised received : 10.11 .2017

Accepted : 28.12.2017

\begin{abstract}
Aim : To determine if stable isotope analysis is a viable tool for authenticating the geographical origin of seafood purchased from the market. The carbon and nitrogen isotope values of samples were analysed to determine if they differ according to their source.
\end{abstract}

Methodology : One set of barramundi samples were purchased from three different markets and another set was obtained directly from a farm. Two sets of tiger prawn samples were obtained from the same markets as the barramundi. These samples were then analysed using isotope ratio mass spectrometry to determine their carbon and nitrogen isotopic values.

Results : The barramundi samples showed significant differences between sources in both the $\delta^{13} \mathrm{C}(<0.05)$ and $\delta^{15} \mathrm{~N}$ $(<0.05)$ values. Similarly, the tiger prawn samples also showed significant differences between sources in the $\delta^{13} \mathrm{C}<<$ $0.05)$ and $\delta^{15} \mathrm{~N}(\mathrm{p}$-value $<0.05)$ values.

Interpretation : This pilot study successfully distinguished between barramundi samples and tiger prawns from different geographical locations. We recommend that further studies be conducted with a higher number of samples, and multiple sites from different geographic regions, and to account for factors influencing the $\delta^{13} \mathrm{C}$ and $\delta^{15} \mathrm{~N}$ values. This study highlights the potential of isotopic analysis as a tool for policy makers and regulatory bodies to verify seafood provenance and enforce industry compliance for source labelling of seafood products.

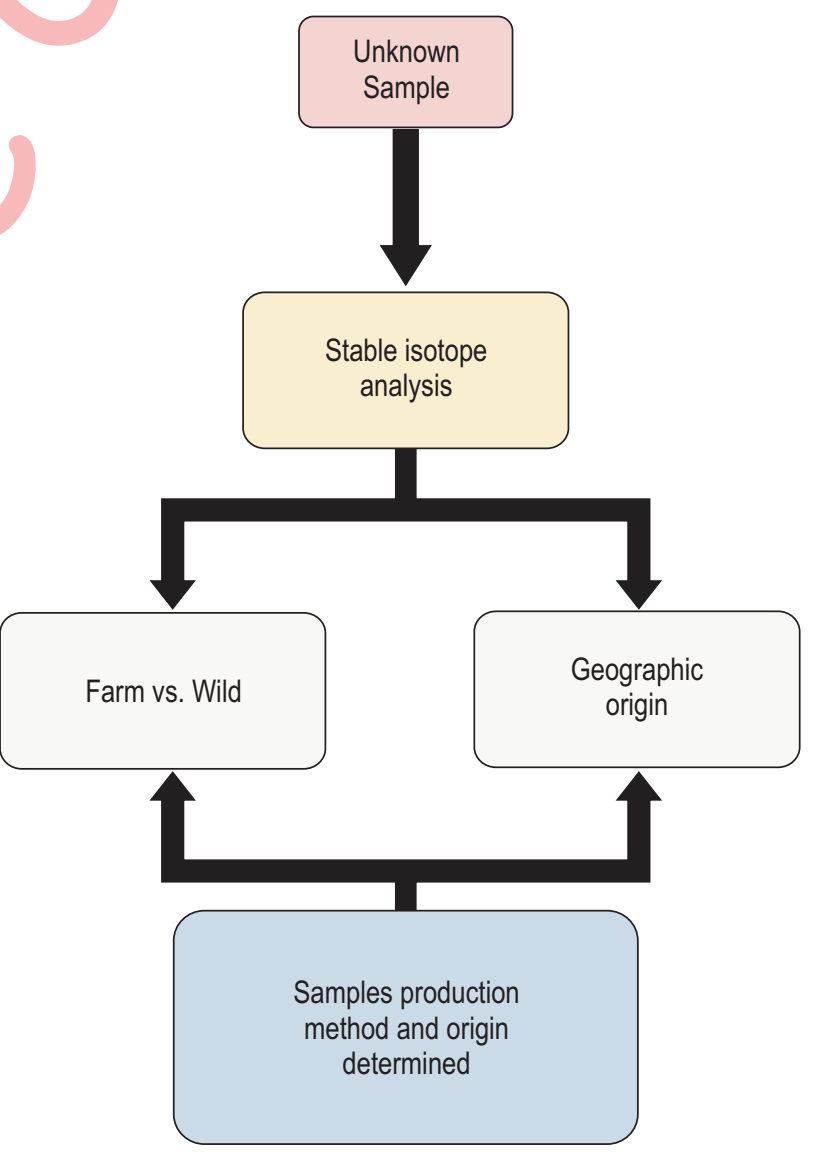




\section{Introduction}

The global population is predicted to increase to around 8 to 11 billion by 2050 (Ezeh et al., 2012). Along with the increase in global population, there will be a commensurate increase in food consumption, most of which will consist of an increased intake of seafood (FAO, 2014). During 2014, the annual consumption of fishery products was estimated to be 146 million tonnes, which rose from 128 million tonnes in 2010 to 136 million tonnes in 2012 (FAO, 2016). Seafood has been recommended as a component of nutritious diet because it is considered to be an essential source of omega-3 fatty acids, high-value protein, vitamins and iodine (Sioen et al. 2007; World Health Organization, 2003). The importance of seafood is highlighted by the market value of fisheries-based industries, which is collectively around $\$ 94$ billion USD. With seafood consumption increasing on a global scale, and with $44 \%$ of the world's fisheries being fully to heavily exploited, the only sustainable solution is the use of aquaculture to support demand (Botsford et al., 1997; Kearney, 2010).

Food traceability or authentication has emerged as a major concern for both consumers and government bodies at a global scale. This is largely due to concern over food safety, hygiene and accuracy of labelling of imported products (Furness and Osman, 2006). Food traceability has been defined as "the ability to trace and follow a food, feed, food-producing animal or substance intended to be, or expected to be incorporated into a food or feed, through all stages of production, processing and distribution" (European Union, 2002). Food fraud is estimated to cost the global food industry around $\$ 40$ billion USD per annum and recent regulatory efforts, such as the European Union's General Food Law Regulation, necessitates a system of tracing food accurately and effectively (European Union, 2002). Furthermore, the production methods of seafood are also under scrutiny by consumers who want more environmentally friendly products (Kelly, 2003).

Australia is one of the leading importers of seafood in the Australasian region; over $72 \%$, or about 200,000 tonnes, of the seafood consumed in Australia is imported from overseas. This number is expected to increase to 500,000 tonnes in the next 15 years to meet consumer demand (Grant, 2011). This raises some issues about food provenance, as substances which are banned in Australia, such as antibiotics, were found in imported seafood in 2012. Recently, the Australian Government banned the import of raw green prawns into Australia, due to an outbreak of white spot disease in South East Queensland prawn farms. To date, the origin of the disease is unknown but it is speculated to have originated from imported seafood products or possibly formulated prawn feed or its associated ingredients. Such issues with the quality and safety of imported seafood (as well as products such as fishmeal) highlight the need for a reliable method of tracing and authenticating the quality of seafood. Authentication and traceability of seafood products, as well as fish feed ingredients, is also important for local aquaculture industries, as well as commercial and recreational fishers.

Stable Isotope Analysis (SIA) uses isotopes assimilated into animal tissues to provide quantitative data, which can be used to distinguish between samples (Meier-Augenstein, 2010). Isotopes are elements that have the same number of protons but different numbers of neutrons. Animals that consume primary producers and other sources of nutrients have distinct isotopic compositions and incorporate these isotopic signatures into their own tissues, although fractionated to a largely predictable extent (Ehleringer et al., 1986). These consumers, therefore, reflect the ratios of the food sources they assimilate, and this is integrated over the time required for elemental turnover in their tissues (Anderson etal., 1987; Kling et al., 1992).

SIA has been utilised previously in seafood traceability with some caveats. For instance, Fasolato et al. (2010) used $\delta^{13} \mathrm{C}$ analysis of fat-free muscle to distinguish between farmed and wild caught Sea Bass because the $\delta^{13} \mathrm{C}$ shows the feeding habit of these fish. Moreover, $\delta^{13} \mathrm{C}$ was selected on the basis of past work by Sweeting et al. (2007) who concluded that there was a minimal seasonal variation in the ratio of $\delta^{13} \mathrm{C}$, especially in large predatory fish. However, a study conducted on wild caught and farmed Brazilian freshwater cachara (Pseudoplatystoma fasciatum) suggested that there is seasonal variability in the carbon to nitrogen $(\mathrm{C}: \mathrm{N})$ ratio, especially in the wet season and the $\mathrm{C}: \mathrm{N}$ ratio was indistinguishable in the dry season. The dietary reasons why the nutritional quality of farmed fish was higher, as well as the lack of variability in the $\mathrm{C}: \mathrm{N}$ ratios in the dry season needs further research (Sant'Ana et al., 2010). However, these contrasting results suggest that using SIA alone, without further studies, may not be adequate to distinguish the geographic origins of seafood. Carter et al. (2015) analysed hydrogen and oxygen stable isotopes in the water recovered from frozen prawns to differentiate between Australian and imported prawns. The oxygen and hydrogen analysis of water alone was unable to distinguish between Australian and imported samples. Moreover, there was no correlation between the stable carbon and nitrogen isotopic values of prawn tissue. This was more than likely due to water being added through the freezing process (Carter et al., 2015). However, the $\delta^{13} \mathrm{C}$ values provided a reliable method of distinguishing between the Australian and imported prawns. Turchini et al. (2009) used carbon, nitrogen and oxygen stable isotopes, as well as chemical analyses to discriminate between different prawn farms. While the study was unable to use water alone to authenticate the origins of the prawns, it demonstrated that non-destructive sampling of seafood was possible. Such studies highlight the importance of developing SIA through further research to determine its utility in provenance authentication.

The objective of this study was to determine if SIA is a viable tool for determining seafood provenance for two commonly imported species. The study used samples of barramundi, Lates 
calcarifer (hereon referred to as barramundi) and the Giant tiger prawn, Penaeus monodon (hereon referred to as tiger prawns), to test the hypothesis that stable isotope signatures differ consistently between conspecific samples of different origin. Barramundi is a valuable fish in Australia for both commercial and recreational fishing and are typically found in estuaries with open access to the sea in tropical and subtropical latitudes. It is a catadromous species that migrates from estuaries to the sea to spawn (Davis, 1986). Similarly, the tiger prawn is also a highly commercially valuable species in Australia and South-East Asia (CSIRO, 2017), where it is farmed or wild-caught.

\section{Materials and Methods}

Three individual barramundi fillets labelled as a farmed product of Taiwan were purchased from three different markets in Sydney, New South Wales. Additionally, three individual barramundi fillets were purchased from a farm in Malaysia through an agent. The fillets were of similar size $(\sim 22 \mathrm{~cm})$. Similarly, farmed tiger prawns labelled as products of Australia and Thailand, which were also purchased from the same three markets. The tiger prawns were also similar in size to each other $(\sim 9 \mathrm{~cm})$. We were unable to verify the accuracy of the labels with respect to provenance.

In the laboratory, all samples were subsequently washed with de-ionised water and frozen until analysis. The samples were thawed and white muscle tissue from the dorsum was removed using a clean stainless-steel blade. Hesslein et al. (1993) showed that the dorsal muscle tissue is the most reliable indicator of the overall isotope values in fish, and sampling of the dorsal muscle has become the standard in this field of research (Mazumder et al., 2008). The tissue samples were placed in clean petri dishes and dried at $\sim 60^{\circ} \mathrm{C}$ for $48 \mathrm{hrs}$; the dried samples were then ground into a fine powder using a mortar and pestle, which were cleaned with ethanol between each sample (Mazumder et al., 2016). The powdered samples were then loaded into tin capsules and compacted manually to remove air spaces (Mazumder et al., 2008).

The isotopic analysis was conducted at the Australian Nuclear Science and Technology Organisation (ANSTO) in Sydney, Australia using a continuous-flow isotope ratio mass spectrometer (CF-IRMS) model Delta V Plus (Thermo Scientific Corporation, U.S.A.), interfaced with an elemental analyser (Thermo Fisher Flash 2000 HTEA, Thermo Electron Corporation, U.S.A.). All data were reported relative to IAEA (International Atomic Energy Agency) secondary standards and were certified relative to air for nitrogen and VPDB (Vienna-PeeDee Belemnite) for carbon. Atwo-point calibration was used to normalise the data, using standards that bracket the analysed samples. Two quality control references (standards) were included in each run of samples. All results were accurate to $1 \%$ for both carbon and nitrogen isotope values and \pm 0.3 parts per thousand $(\%)$ for $\delta^{13} \mathrm{C}$ and $\delta^{15} \mathrm{~N}$. All results were reported in delta $(\delta)$ units in parts per thousand $(\%)$ determined using the formula below:

$$
x\left(\%_{00}\right)=\left(\frac{\text { Rsample }}{\text { Rstandard }}-1\right) \times 1000
$$

Lipid extraction is generally not carried out as it only changes the stable carbon isotope values by $0.4 \% 0-1.0 \%$ in adult fish (Sotiropoulos, Tonn \& Wassenaar, 2004). In this study, we used the formula given by Post et al. (2007), to correct lipids, if the C:N ratio was greater than 3.5 to normalise the lipid content of the tissues:

$\delta^{13} \mathrm{C}$ normalised $=\delta^{13} \mathrm{C}$ untreated $-3.32+0.99 \times \mathrm{C}: \mathrm{N}$

All data were analysed using Rstudio (RStudio Team 2016). T-tests were used to determine if the difference in means between the two sets of samples collected from different geographical locations were significantly different.

\section{Results and Discussion}

The samples showed very strong differences in nitrogen and carbon stable isotopes. The differences in the carbon isotopic values of Taiwanese barramundi (-19.36 \pm 0.31 , ranging from 19.14 to -19.72$)$ was significantly enriched $(<0.05)$ compared to the Malaysian barramundi ( $-21.8 \pm 0.08$, ranging from -21.71 to 21.86). Similarly, the differences in nitrogen isotopic values from the Taiwanese barramundi $(10.53 \pm 0.15$, ranging from 10.4 to $10.7)$ were significantly enriched $(<0.05)$ when compared with the Malaysian barramundi ( $8.92 \pm 0.04$, ranging from 8.9 to 8.97 ) (Fig. 1A).

The carbon isotopic values of tiger prawns from Australia $(-20.04 \pm 0.12$, ranging from -19.9 to -20.11$)$ were significantly enriched $(<0.05)$ compared to the prawns from Thailand $(-21.16 \pm$ 0.17 , ranging from -20.97 to -21.31$)$. The nitrogen values of the Australian prawns ( $8.27 \pm 0.35$, ranging from 7.9 to 8.6$)$ were significantly enriched ( $p$-value: $<0.05$ ) from the prawns from Thailand $(7.07 \pm 0.25$, ranging from 6.8 to 7.3$)$ (Fig. 1B).

The findings of this study highlights the value to further develop this technique as a tool in seafood authentication. This study is unique in the sense that it has relied solely on the utilisation of SIA, whereas most previous studies have used multiple techniques to achieve a similar result.

Busetto et al. (2008) used the fatty acid composition and SIA to distinguish between the production method and geographic origin of Psetta maxima. It was recommended that using SIA in combination with fatty acid composition to distinguish between the tested geographic origins (Busetto et al., 2008). Since SIA is a rapid method of analysis, it was suggested this would be ideal to distinguish between the wild-caught samples from different origins. Other studies, such as Turchini et al. (2009), showed that SIA alone was capable of distinguishing between fish 

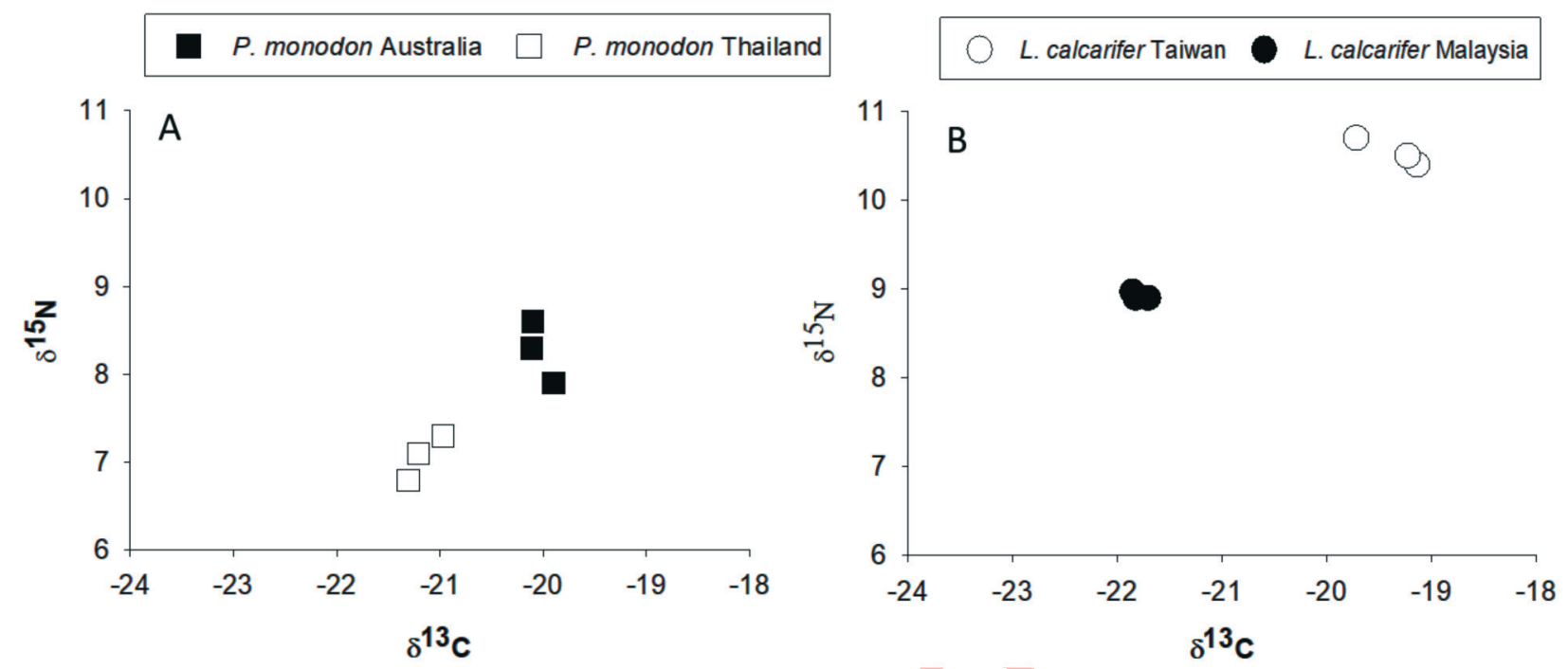

Fig. 1: Stable carbon and nitrogen isotope values of finfish and prawn analysed from different geographical locations. Panel Ashows the stable isotopic values of tiger prawns (Penaeus monodon) and panel B shows the stable isotopic values of barramundi (Lates calcarifer)

produced from different farms due to variability in their diets. The study also showed that SIA was more reliable than traditional methods, such as fatty acid profiling. However, to fully test the utility of SIA for determining seafood provenance, more samples from wild-catch fisheries and farms are needed, particularly to understand if seasonal variability and other factors would decrease the accuracy of the analysis.

Both the analyzed barramundi and tiger prawn samples had significantly different $\delta^{13} \mathrm{C}$ and $\delta^{15} \mathrm{~N}$ values, and hence it could be stated that samples from different source regions can have widely different stable isotope signatures. The Taiwanese barramundi did not come from authenticated origins, but the Malaysian samples were authenticated as they were purchased from their source. Since neither of the tiger prawn samples were from authenticated sources, without further data and studies it is not possible to confidently identify the driving factors behind their differences.

The nitrogen isotopic values of the Taiwanese barramundi were enriched compared to the Malaysian farmderived samples. There are two potential explanations for this. First, if they were produced in a farm, then their dietary source of nitrogen consisted of a higher $\delta^{15} \mathrm{~N}$ value feed when compared to the authenticated Malaysian barramundi. If the Taiwanese barramundi were wild-caught, then the nitrogen isotopic values would suggest that their diets consisted of organisms from a higher trophic level. Since the Taiwanese samples were not authenticated it cannot be determined which scenario is more likely. A similar conclusion can be drawn regarding the tiger prawn samples from Australia. However, as neither the Australian nor the Thai tiger prawns were from authenticated sources it cannot be assumed that their dietary sources alone can explain the variation and nor can other factors such as pollution in the environment affecting the $\delta^{15} \mathrm{~N}$ value be ruled out (Mazumder et al., 2011; Saintilan and Mazumder, 2017).

The carbon isotope values of the Taiwanese barramundi were enriched when compared to the samples from Malaysia. The carbon isotopic values of Taiwanese barramundi indicates that the dietary sources probably consisted of a mixture of variable C3 and C4 plant-based materials or even seagrassbased nutrients. This can then be compared with SIA values of wild-caught samples from different marine organisms in the Matang Mangrove Estuary, Malaysia. The top predatory fishes in this ecosystem were perch (Johnius belangerii) $\left(\delta^{13} \mathrm{C}:-19.48 \pm\right.$ $0.94)$ and Indian threadfin (Leptomelanosoma indicum) $\left(\delta^{13} \mathrm{C}\right.$ : $17.93 \pm 1.43$ ). When the Taiwanese barramundi samples were compared to these fish it suggested that they were more likely to be wild-caught samples; however, without further data it was not possible to accurately determine if this was the case. The carbon isotope values of the Taiwanese barramundi also suggest that the dietary carbon of the fish was from a marinebased source (Chisholm et al., 1982). Additionally, given that the Malaysian samples were authenticated, the carbon isotopic values indicate that the fish were farmed under freshwater conditions. Therefore, the carbon isotopic values also provided some information regarding not only the geographic origin but also the production method. A similar conclusion can be drawn for the tiger prawns; however, because authenticated samples were not analysed, the dietary sources and production methods of these prawns cannot be determined (Mazumder et al., 2011; Saintilan and Mazumder, 2017). 
Previous studies had varying success in identifying the origin of seafood using SIA. Kim et al. (2015) used samples obtained from the market, and their catchment area and country of origin were confirmed. These samples were then used for cytochrome oxidase sequencing to determine the species of shrimp and fish, which helped to distinguish their geographic origins. Additionally, SIA revealed differences in their $\delta^{13} \mathrm{C}$ and $\delta^{15} \mathrm{~N}$ for some geographic origins. However, for some samples such as wild-caught hairtail from Korea and India had similar values. Our pilot isotopic analysis suggests that geographic variation in sample sources might be identifiable. To precisely understand the entire isotopic variability, more samples will be needed from authenticated sources with additional environmental and production method data.

Consumers are also concerned regarding the production methods used to produce seafood (Kelly, 2003). For this study, all samples, except the Malaysian barramundi, were obtained from the market, where it was not possible to authenticate the labelling. Molkentin et al. (2007) studied the use of SIA of the $\delta^{13} \mathrm{C}$ and $\delta^{15} \mathrm{~N}$ ratio to differentiate between wild-caught salmon or those that were either conventionally or organically farmed. They found that a combination of linoleic acid and SIA was necessary to distinguish between the three different production methods of the Atlantic salmon. Later work by Molkentin et al. (2015) successfully used SIA to determine the production methods for Atlantic salmon and trout.

In conclusion, this pilot study used a small number of samples to investigate the potential use of SIA as a method of seafood provenance. The results of this analysis are positive in the sense that they can clearly distinguish between the geographic regions of both barramundi and tiger prawns. However, the sole use of SIA was unable to precisely identify the production methods and to understand all the variables influencing these differences. Future studies should utilise a higher number of authenticated samples along with other variable data, such as season of collection, environmental conditions, diet sources and production methods. When all the different variables are known, the use of SIA could potentially distinguish between not only the geographic origins but also the production method of seafood.

\section{Acknowledgments}

The authors thank the Australian Nuclear Science and Technology Organisation (ANSTO) for providing and covering the cost of the analyses. We would also like to thank Simon Rowe (Ocean Watch, Australia) for helping to purchase samples. Barbora Gallagher and Jennifer van Holst (ANSTO) for carrying out the isotopic analysis.

\section{References}

Anderson, R.K., P.L. Parker and A. Lawrence: $\mathrm{A}^{13} \mathrm{C} /{ }^{12} \mathrm{C}$ tracer study of the utilization of presented feed by a commercially important shrimp
Penaeus vannamei in a pond growout system. J. World Aquacult. Soc., 18, 148-155 (1987).

Botsford, L.W., J.C. Castilla and C.H. Peterson: The management of fisheries and marine ecosystems. Science, 277, 509-515 (1997).

Busetto, M.L., V.M. Moretti, F. Caprino, I. Giani, F. Bellagamba, J.M. Moreno-Rojas, C. Guillou and R. Malandra: Authentication of farmed and wild turbot (Psetta maxima) by fatty acid and isotopic analyses combined with chemometrics. J. Agricult. Food Chem., $56,2742-2770$ (2008).

Carter, J.F., U. Tinggi, X. Yang and B. Fry: Stable isotope and trace metal compositions of Australian prawns as a guide to authenticity and wholesomeness. Food Chem., 170, 241-248 (2015).

Chisholm, B.S., D.E. Nelson and H.P. Schwarcz: Stable-carbon isotope ratios as a measure of marine versus terrestrial protein in ancient diets. Science, 216, 1131-1132 (1982).

CSIRO: Case study: Black tiger prawn. Commonwealth Scientific and Industrial Research Organisation, viewed $7^{\text {th }}$ August 2017, $<$ <ttps://www.csiro.au/en/Research/AF/Areas/Aquaculture/Premi um-breeds/Black-tiger-prawn>.

Davis, T.L.O.: Migration patterns in barramundi, Lates calcarifer (Bloch), in Van Diemen Gulf, Australia, with estimates of fishing mortality in specific areas. Fish. Res., 4, 243-58 (1986).

Ehleringer, J.R., P.W. Rundel and K.A. Nagy: Stable isotopes in physiological ecology and food web research. Trends Ecol. Evol., 1,42-45 (1986)

European Union: REGULATION (EC) No 178/2002 OF THE EUROPEAN PARLIAMENT AND OF THE COUNCIL of 28 January 2002 laying down the general principles and requirements of food law, establishing the European Food Safety Authority and laying down procedures in matters of food safety. Official Journal of the European Communities (2002).

Ezeh, A.C., J. Bongaarts and B. Mberu: Global population trends and policy options. The Lancet, 380, 142-148 (2012).

FAO (Food and Agriculture Organization): FAO yearbook. Fishery and Aquaculture Statistics. 2014, Rome, viewed $3^{\text {rd }}$ August 2017, $<$ <ttp://www.fao.org/3/a-i5716t.pdf>.

Fasolato, L., E. Novelli, L. Salmaso, L. Corain, F. Camin, M. Perini, P. Antonetti and S. Balzan: Application of nonparametric multivariate analyses to the authentication of wild and farmed European sea bass (Dicentrarchus labrax). Results of a survey on fish sampled in the retail trade. J. Agricult. Food Chem., 58, 10979-88 (2010).

Furness, A. and K.A. Osman: Developing traceability systems across the food supply chain: An overview. Improving Traceability in Food Processing and Distribution, pp. 3-25 (2006). doi: https://doi. org/ 10.1533/9781845691233.1.3.

Grant, N.: Submission to the Development of a National Food Plan by the Seafood Importers Association of Australasia Inc. Department of Agriculture and Water Resources, Australia (2011).

Hesslein, R.H., K.A. Hallard and P. Ramlal: Replacement of sulfur, carbon, and nitrogen in tissue of growing broad whitefish (Coregonus nasus) in response to a change in diet traced by $\delta^{34} \mathrm{~S}$, $\delta^{13} \mathrm{C}$, and $\delta^{15} \mathrm{~N}$. Can. J. Fish. Aquat. Sci., 50, 2071-2076 (1993).

Kearney, J.: Food consumption trends and drivers. Philosophical Trans. Royal Soc. B: Biol. Sci, 365, 2793 (2010).

Kelly, S.D.: 7 - Using stable isotope ratio mass spectrometry (IRMS) in food authentication and traceability. Food Authenticity and Traceability, pp. 156-83, (2003). doi: https://doi.org/10.1533/ 9781855737181.1.156.

Kim, H., K.S. Kumar, S.Y. Hwang, B.C. Kang, H.B. Moon and K.H. Shin: 
Utility of stable isotope and cytochrome oxidase I gene sequencing analyses in inferring origin and authentication of hairtail fish and shrimp. J. Agricult. Food Chem., 63, 5548-5556 (2015).

Kling, G.W., B. Fry and W.J. O'Brien: Stable isotopes and planktonic trophic structure in arctic lakes. Ecology, 73, 561-6 (1992).

Mazumder, D., N. Saintilan, R. Williams and R. Szymczak: Trophic importance of a temperate intertidal wetland to resident and itinerant taxa: Evidence from multiple stable isotope analyses. Mar. Freshw. Res., 62, 11-19 (2011).

Mazumder, D., R. Williams, L. Wen, N. Saintilan and C. Walsh: Impoundment constraint of fish niche diversity in a temperate Australian river. Hydrobiologia, 771, 195-206 (2016).

Mazumder, D., R.J. Williams, D. Reid, N. Saintilan and R. Szymczak: Variability of stable isotope ratios of glassfish (Ambassis jacksoniensis) from mangrove/saltmarsh environments in southeast Australia and implications for choosing sample size. Environ. Bioind., 3, 114-23 (2008).

Meier-Augenstein, W.: Stable isotopic distribution and isotopic fractionation of light elements in nature'. In : Stable Isotope Forensics. John Wiley \& Sons, Ltd., pp. 16-35 (2010).

Molkentin, J., I. Lehmann, U. Ostermeyer and H. Rehbein: Traceability of organic fish - Authenticating the production origin of salmonids by chemical and isotopic analyses. Food Control, 53, 55-66. (2015).

Molkentin, J., H. Meisel, I. Lehmann and H. Rehbein: Identification of organically farmed Atlantic salmon by analysis of stable isotopes and fatty acids. European Food Res. Technol., 224, 535-43 (2007).
Post, D.M., C.A. Layman, D.A. Arrington, G. Takimoto, J. Quattrochi, C.G. Montaña and J. Rosenheim: Getting to the fat of the matter: Models, methods and assumptions for dealing with lipids in stable isotope analyses. Oecologia, 152, 179-89 (2007).

Rstudio Team: RStudio: Integrated Development Environment for R, RStudio, Inc., Boston, MA(2016).

Saintilan, N. and D. Mazumder: Mass spawning of crabs: Ecological implications in subtropical Australia. Hydrobiologia, 803, 239-250 (2017).

Sant'Ana, L.S., C. Ducatti and D.G. Ramires: Seasonal variations in chemical composition and stable isotopes of farmed and wild Brazilian freshwater fish. Food Chem., 122, 74-77 (2010)

Sioen, I., C. Matthys, G. De Backer, J. Van Camp and S.D. Henauw: Importance of seafood as nutrient source in the diet of Belgian adolescents. J. Human Nutr. Diete., 20,580-589 (2007).

Sotiropoulos, M.A., W.M. Tonn and L.I. Wassenaar: Effects of lipid extraction on stable carbon and nitrogen isotope analyses of fish tissues: Potential consequences for food web studies. Ecol. Fresh. Fish, 13, 155-60 (2004).

Sweeting, C.J., J.T. Barry, N.V.C. Polunin and S. Jennings: Effects of body size and environment on diet-tissue $\delta 13 \mathrm{C}$ fractionation in fishes. J. Exp. Mar. Biol. Ecol., 352, 165-76 (2007).

Turchini, G.M., G.P. Quinn, P.L. Jones, G. Palmeri and G. Gooley: Traceability and discrimination among differently farmed fish: $\mathrm{A}$ case study on Australian Murray Cod. J. Agricult. Food Chem., 57, 274-81 (2009).

World Health Organization: Food based dietary guidelines in the WHO European Region, Copenhagen, Denmark, WHO (2003). 